\title{
CORRIGENDUM
}

\section{T-cell quality in memory and protection: implications for vaccine design}

Robert A. Seder, Patricia A. Darrah and Mario Roederer

Nature Reviews Immunology 8, 247-258 (2008)

In Figure 5 b and Figure 5c, the terms "high" and "low" were reversed. A corrected version of the Figure is available below.

a CD8 ${ }^{+}$-cell quality

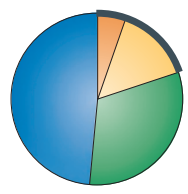

DNA

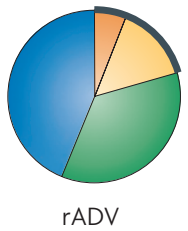

b CD4+ T-cell quality

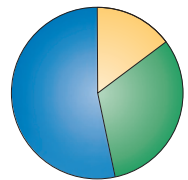

High rADV

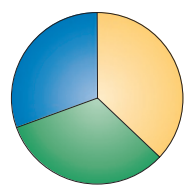

Low rADV

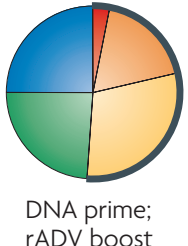

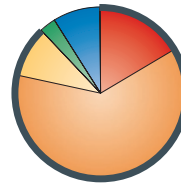

DNA prime; NYVAC boost

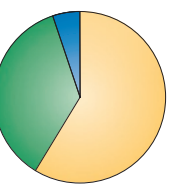

Live infection

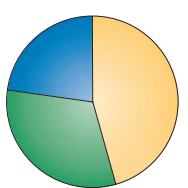

Protein
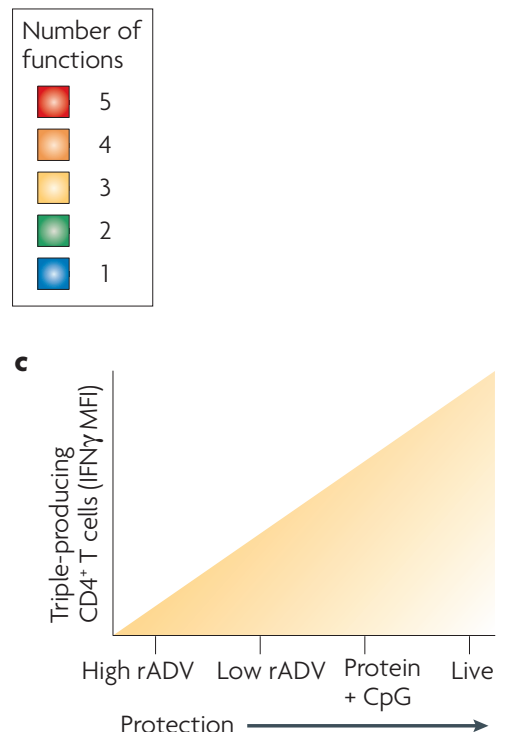

Figure 5 | The impact of vaccine formulation on T-cell quality. a | The quality of CD8 ${ }^{+}$T-cell responses (five functions measured) to the HIV envelope protein in humans is illustrated following immunization with DNA or replicationdefective recombinant adenovirus ( $(\mathrm{ADV}$ ) vectors containing the protein, or after priming with the DNA vector followed by boosting with rADV or poxvirus vectors (New York vaccinia (NYVAC)). The black arcs highlight the fraction of the multifunctional (3-5-expressing) $C D 8^{+} T$ cells within each response. $\mathbf{b} \mid$ The quality of the $C D 4^{+} T$-cell response (3 functions measured) to Leishmania major proteins is shown following immunization with low- or high-dose rADV vaccines, protein vaccine with $\mathrm{CpG}$-containing motifs, or live infection. $\mathbf{c}$ |Comparing only triple-cytokine-producing $\mathrm{CD}^{+} \mathrm{T}$ cells induced by each vaccination reveals a hierarchy of IFN $\gamma$ median fluorescence intensity (MFI) that correlates with the level of protection following subsequent challenge with L. major. 